\title{
Efeitos do processo de convergência às normas internacionais de contabilidade no value relevance das demonstrações contábeis de organizações brasileiras
}

\section{Effects of the convergence process to international accounting standards in value relevance of financial statements of brazilian organizations}

Efectos del proceso de convergencia a las normas internacionales de contabilidad en el value relevance de las demostraciones contables de organizaciones brasileñas

\section{Alexandre Corrêa dos Santos}

Mestre em Contabilidade pela Universidade Regional de Blumenau

Endereço: Rua Padre Vitoriano Valente, $n^{\circ} 2012$, Boa Vista I

CEP: 86200-000 - Ibiporã/PR - Brasil

E-mail: alexandre@viawork.com.br

Telefone: (43) 3026-7434

\section{Loriberto Starosky Filho}

Mestre em Contabilidade pela Universidade Regional de Blumenau

Professor da UNIFEBE Centro Univ. Brusque e do Inst. Cenecista Fayal de Ensino Superior

Endereço: Rua Hugo Loth Junior, $n^{\circ} 167$, Fortaleza

CEP: 89056-450 - Blumenau/SC - Brasil

E-mail: prof.loriberto@gmail.com

Telefone (47) 9982-0533

\section{Roberto Carlos Klann}

Doutor em Ciências Contábeis e Administração pela Universidade Regional de Blumenau Professor do Programa de Pós-Graduação em Ciências Contábeis na Fundação Universidade Regional de Blumenau (FURB)

Endereço: Rua Antônio da Veiga, $n^{\circ} 140$, Victor Konder

CEP: 89012-900 - Blumenau/SC - Brasil

E-mail: rklann@furb.br

Telefone: (47) 3321-0200

Artigo recebido em 09/09/2013. Revisado por pares em 02/02/2014. Reformulado em 08/03/2014. Recomendado para publicação em 24/03/2014 por Sandra Rolim Ensslin (Editora Científica). Publicado em 08/04/2014. 


\title{
Resumo
}

O objetivo deste estudo é identificar de que forma o processo de convergência às normas contábeis internacionais impactou o value relevance das informações contábeis evidenciadas por companhias abertas brasileiras. Este estudo é caracterizado como descritivo, documental e com abordagem quantitativa. Foram analisadas 118 empresas brasileiras listadas na BM\&FBovespa, compreendendo dados de 2006 a 2011, com base no modelo de Barth, Landsman e Lang (2008). De maneira geral, os resultados mostram aumento no value relevance das demonstrações contábeis de empresas brasileiras após a convergência. No entanto, é possível que outros fatores relacionados a características institucionais do país tenham influenciado tais resultados.

Palavras-chave: Convergência contábil. Demonstrações contábeis. Value relevance.

\begin{abstract}
The objective of this study is to identify how the convergence to international accounting standards has impacted the value relevance of accounting information revealed by Brazilian companies. This study is characterized as descriptive, documentary and with quantitative approach. We have analyzed 118 Brazilian companies listed on BM\&FBovespa, comprising data between 2006 to 2011, based on model of Barth, Landsman and Lang (2008). In general, the results indicate an increase in the value relevance of financial statements in Brazilian companies. However, it is possible that others factors related to country institutional features have influenced these results.
\end{abstract}

Keywords: Accounting convergence. Financial statements. Value relevance.

\section{Resumen}

Este estudio pretende identificar de que forma el proceso de convergencia a las normas contables internacionales ha impactado el valuereference de las informaciones contables evidenciadas por compañías abiertas brasileñas. El estudio es clasificado como descriptivo, documental y con abordaje cuantitativo. Fueron analizadas 118 empresas brasileñas listadas en BM\&FBovespa, comprendiendo datos de 2006 a 2011, con base en el modelo de Barth, Landsman y Lang (2008). De una manera general, los resultados indican aumento en el valuerelevance de las demostraciones contables de empresas brasileñas después de la convergencia. Sin embargo, es posible que otros factores relacionados a características institucionales del país hayan influenciado dichos resultados.

Palabras clave: Convergencia contable. Demostraciones contables. Value relevance. 


\section{Introdução}

A convergência às normas do International Accountant Standards Board - IASB tem como objetivo melhorar a qualidade da informação contábil reportada pelas empresas, minimizando situações de conflito e assimetria, explicadas pela teoria da agência. Uma das formas de verificar se essa melhoria está ocorrendo efetivamente é observando se as informações contábeis evidenciadas pelas empresas estão mais fortemente correlacionadas ao preço de mercado de suas ações no período pós-convergência, ou seja, se os investidores ou o mercado em geral, passam a dar maior importância às informações divulgadas pelas companhias, refletindo no preço de mercado da ação, o que tem sido chamado na literatura internacional de value relevance.

Nesta linha, Beisland (2009) afirma que as pesquisas sobre value relevance investigam empiricamente a utilidade das informações contábeis para os investidores em ações, sendo considerada como relevante se há uma associação estatística entre os números contábeis e os valores de mercado das ações.

Estudos sobre value relevance precedem a fase de difusão das normas internacionais de contabilidade, as chamadas International Financial Reporting Standards (IFRS). Barth, Beaver e Landsman (2001) corroboram que na literatura existente uma conta contábil é definida como valor relevante quando tem uma associação de previsão com valores do mercado de capital e, embora a literatura que examina essas associações se estenda há mais de 30 anos (MILLER; MODIGLIANI, 1966), o primeiro estudo que se tem conhecimento que usa "relevância de valor" para descrever essa associação é o de Amir, Harris e Venuti (1993).

A partir dos anos 2000, após a ampliação da adoção das normas internacionais de contabilidade (IFRS) em diversos países, tem crescido o volume de estudos que investigam o impacto das IFRS no value relevance. Trabalhos como o de Gjerd, Knivsfla e Saetem (2008), Agostino, Drago e Silipo (2010), Filip (2010) e Clarkson et al. (2011) estudaram os efeitos da adoção por países signatários, encontrando resultados que contribuíram tanto para aspectos empíricos nas organizações, quanto para a consolidação do constructo teórico relacionado à temática.

Neste contexto, surge a seguinte questão de pesquisa: De que forma o processo de convergência às normas contábeis internacionais tem impactado o value relevance das informações contábeis reportadas por companhias brasileiras?

A pesquisa objetiva identificar de que forma o processo de convergência às normas contábeis internacionais impactou o value relevance das informações contábeis evidenciadas por companhias brasileiras.

A justificativa do presente estudo está fundamentada na importância do processo de convergência contábil internacional que está sendo implantado no Brasil. Esse processo representa uma modificação significativa no modo de reconhecer, mensurar e evidenciar informações contábeis aos diversos stakeholders. Portanto, identificar se esse esforço vem produzindo resultado, em termos de melhoria na qualidade da informação contábil divulgada, pode auxiliar na continuidade e expansão da convergência no Brasil.

Nesse sentido, este estudo procura contribuir para a identificação dos efeitos da adoção das novas normas contábeis, convergentes com as normas contábeis internacionais, no preço das ações de companhias brasileiras. Com isso, pode fornecer um retrato da percepção do investidor em relação a esse processo. As pesquisas que analisam a relação entre a informação contábil divulgada e as variações nos preços das ações têm sido chamadas de 
estudos sobre value relevance. Caso haja maior relação entre a informação contábil e o preço ou retorno das ações no mercado, pode-se inferir que houve melhoria na informação divulgada após a convergência. Caso contrário, pode-se inferir que o processo de convergência às normas do $I A S B$ não alterou a qualidade dos relatórios contábeis.

Além disso, pode-se levantar uma nova questão de pesquisa, procurando entender os motivos do não reconhecimento pelo mercado do aumento na qualidade da informação contábil propagada pelo próprio $I A S B$.

\section{Referencial Teórico}

Nesta seção apresentam-se as abordagens teóricas que sustentam o desenvolvimento da pesquisa, visando o alcance do objetivo proposto. Nesse sentido, busca-se na teoria da agência e na assimetria da informação suporte teórico que ajude a explicar as variações no value relevance das informações contábeis após a convergência, considerando que um dos objetivos desse processo é reduzir a assimetria informacional entre os gestores e os demais usuários da informação contábil.

\subsection{Teoria da Agência}

As organizações possuem diferentes formas de controle, exercidos por seus acionistas ou delegados para terceiros, os gestores. A partir do momento em que ocorre esta outorga, nascem os conflitos entre as partes, que a Teoria da Agência procura entender e explicar.

Neste contexto, Jensen e Meckling (1976) definem uma relação de agência como um contrato pelo qual uma ou mais pessoas (o principal) (s) contrata outra pessoa (o agente) para executar algum serviço em seu nome, que envolve delegar alguma autoridade para a tomada de decisão do agente. Se ambas as partes da relação são maximizadores de utilidade, há boas razões para acreditar que o agente não agirá sempre no melhor interesse do principal. O principal pode limitar as divergências de seu interesse por meio do estabelecimento de incentivos apropriados para o agente e incorrer em custos de controle destinados a limitar as atividades do agente.

Portanto, entre os gestores e os detentores da propriedade existem diversos interesses, e nesses interesses surgem os conflitos, pois nem sempre os agentes (gestores) agem em benefício do interesse principal (acionista).

Neste cenário de interesses divergentes, Rangel e Andrade (2005) comentam que o modelo clássico de Teoria da Agência descreve que empresas modernas possuem propriedade dispersa em ações e que o problema principal é visto como o conflito entre agentes e principais.

O conflito de interesses existe quando alguém não é independente em relação à matéria em discussão, podendo influenciar ou então tomar atitudes e decisões motivadas por interesses distintos aos da organização. A separação das funções e a definição clara de papeis e responsabilidades dos agentes de gestão podem minimizar possíveis focos de conflito de interesses (Instituto Brasileiro de Governança Corporativa - IBGC, 2010).

Diante disso, Carvalhosa (2003) enfatiza que o papel do administrador é de exercer sua atividade no interesse da companhia, em obediência a um dever. Suas decisões deveriam 
ser no sentido de atender os interesses da organização. Assim, este dever legal implica na distinção entre os interesses da organização e os interesses dos principais.

Esta divergência de interesses vem sendo estudada com frequência em trabalhos acadêmicos. Berle e Means abordam o tema em sua obra "A moderna sociedade anônima e a propriedade privada", de 1932, traduzida em 1984. Os autores tratam da divisão de propriedade, em que afirmam que o acionista tem interesses bem definidos no funcionamento da companhia (BERLE; MEANS, 1988).

Segundo Oliveira (2009), o problema de agência traz consequências, como o custo de transação, assimetria da informação e seleção adversa. Os custos de transação compreendem os custos de avaliar, negociar e escrever os contratos (entre o principal e o agente), incluindo as taxas de negociação (WATTS; ZIMMERMAN, 1990).

A assimetria de informação ocorre quando o principal não tem acesso às mesmas informações possuídas pelo agente. Geralmente, as informações recebidas pelo principal são oriundas do agente, o que permite a ele controlar o tipo e a profundidade da informação que será repassada ao principal, surgindo assim, a assimetria informacional (SEGATTOMENDES, 2001).

O problema de seleção adversa, também chamada de hidden information (informações escondidas), segundo Arrow (1985), ocorre quando o agente possui informações que não são observáveis ou são muito caras para que o principal as obtenha. Em consequência, o principal não pode se certificar de que as decisões do agente estejam sendo tomadas em razão de seus interesses (principal).

Em consequência, Dalmacio (2009) explica que os conflitos de interesses ou de agência resultam em custos de monitoramento e alinhamento de interesses, entre o principal e o agente. Por seu turno, Lustosa (2004, p.17), no entanto, comenta que se "pode evitar a seleção adversa por meio da divulgação de informações adicionais por parte das empresas, tanto voluntariamente, ou por determinação do investidor".

Porém, não é tão fácil descobrir quais os interesses entre Agente e Principal. Silveira (2004) ressalta que "a maior parte dos estudos sobre o tema parte do pressuposto fundamental que a principal tarefa dos gestores é tomar decisões que maximizem o valor da empresa, a fim de maximizar a riqueza de toda a empresa".

No entanto, Eisenhardt (1989) considera que o agente e o principal possuem diferentes metas e diferentes atitudes em relação ao risco. Neste sentido, as informações divulgadas pelo agente nem sempre atendem a interesses comuns, ou são incompletas, gerando um problema de assimetria de informação.

Nesse contexto, Berle e Means (1988) argumentam ser importante conhecer os objetivos dos indivíduos no controle antes de se analisar os desejos deles. Rangel e Andrade (2005) afirmam que uma das formas de evitar esse conflito se dá por meio do monitoramento das atividades dos executivos, estabelecendo-se incentivos contratuais apropriados.

\subsection{Assimetria de Informação}

A assimetria de informação é tratada pela Teoria da Agência e também pela Teoria da Sinalização. Dalmácio (2009) destaca que apesar desta última ter se desenvolvido no mercado de trabalho, por meio do trabalho de Spence (1973), ela também tem suas aplicações em outras áreas do conhecimento, inclusive finanças. 
Sob a ótica da Teoria da Sinalização, organizações com intuito de buscar novos investidores sinalizam para o mercado de que elas podem oferecer retorno, além de assegurar sua qualidade e credibilidade informacional. Desta forma, Dalmácio (2009) sugere que a assimetria de informação pode ser reduzida, haja vista que a Teoria da Sinalização busca alternativas para redução da assimetria, aumentando o nível de informações.

Para isso é necessário que se conheça o grau de assimetria da informação, uma vez que a capacidade de se observar o ambiente não é total. Porém, as informações que o principal recebe são fornecidas pelo agente, o que possibilita um controle do tipo e profundidade da informação fornecida (SEGATTO-MENDES, 2001).

Nesse sentido, o IBGC (2010) recomenda que os gestores devam garantir que sejam prestadas aos stakeholders as informações de seu interesse, além das que são obrigatórias por lei ou regulamento, tão logo estejam disponíveis.

O objetivo principal da governança na organização é reduzir a assimetria informacional entre os agentes. Com isto, é possível aumentar a proteção aos acionistas minoritários, de forma a incentivar a sua participação no mercado acionário e reduzir os custos de captação de recursos, com a credibilidade adquirida pela empresa junto a credores e acionistas (SILVEIRA, 2004).

Quando se discute a utilidade da informação contábil, segundo Dias Filho (2000), o termo evidenciação permeia as principais reflexões. A comunicação ou evidenciação possui papel fundamental para diminuir a percepção de assimetria das informações existentes entre gestores e investidores. Para Famá et al. (2005), o disclosure é visto como uma das formas fundamentais dos gestores comunicarem-se com os acionistas e apresentar o desempenho da administração.

Para assegurar que haja simetria, essa comunicação deve ser feita com clareza e prevalecendo a substância sobre a forma. Também se deve buscar uma linguagem acessível ao público-alvo em questão (IBGC, 2010).

\subsection{Processo de Convergência Contábil Internacional no Brasil}

Nos últimos anos diversos países estão passando por um importante processo internacional de alteração nos padrões contábeis, chamado de Convergência Contábil Internacional, que está sendo conduzido pelo $I A S B$, órgão responsável pela normatização e debates sobre o tema em âmbito internacional.

Esse processo contábil, segundo Lemes e Carvalho (2004), representa a busca da contabilidade em atender sua função básica de fornecer informação útil para a tomada de decisão e, subordina-se às necessidades da sociedade e cultura à qual ela serve. Assim, considerando-se que estas culturas são diferentes, suas práticas contábeis também o serão.

Porém, diferentes padrões contábeis tendem a dificultar a interpretação sobre o valor econômico do patrimônio das organizações. Neste contexto, requer-se um sistema normativo contábil mais harmônico, capaz de reduzir essa assimetria informacional. D’Arci (2001) afirma que a existência de diversos padrões contábeis no mercado global pode representar uma barreira às empresas que buscam o mercado internacional.

Em âmbito internacional a harmonização das normas contábeis é um movimento que surge como forma de atender a maximização da utilidade da informação contábil para todos os usuários, principalmente para o mercado de capitais (LEMES; CARVALHO, 2004).

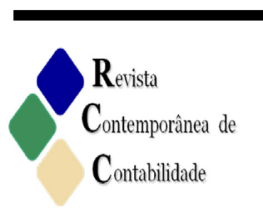

ISSN 2175-8069, UFSC, Florianópolis, v. 11, n. 22, p. 95 -118, jan./abr. 2014 
A expansão dos mercados, segundo Niyama (2005), justifica a harmonização contábil, pelo motivo que uma mesma transação contábil possa ser escriturada de forma diferente, dependendo do país, o que cria dificuldades de análise e comparação de desempenho, além da situação financeira das organizações. Kroenke e Cunha (2008) relatam que o processo de convergência justifica-se pelo papel informativo que a Contabilidade exerce no auxílio da tomada de decisão por seus usuários. Portanto, um entendimento claro das informações contábeis é consequência da clareza das normas em que ela está inserida, pois, diferentes interpretações diminuem a sua credibilidade.

Além disso, Alves e Antunes (2010) comentam que os escândalos nos Estados Unidos da América e na Europa, relacionados com a contabilidade "criativa" de empresas como a ENRON e a Parmalat, criaram a necessidade de geração de informações financeiras confiáveis, como elemento essencial na tomada de decisão pelos agentes dos mercados de capitais.

No Brasil, os marcos legais que editaram as primeiras normativas relacionadas à adoção das Normas Internacionais de Contabilidade foram: as Normas e Procedimentos de Contabilidade (NFC's) editadas pelo IBRACON (2002); a Comunicação $n^{\circ}$ 14.659/2006 do Banco Central; a Instrução CVM no 457/2007; a Circular n ${ }^{\circ}$ 357/07 da Superintendência de Seguros Privados (SUSEP); a Deliberação CVM 609/2009; Lei 11.638 de 28/12/2007, que alterou alguns dispositivos da Lei 6.404/76, (FARIA; QUEIROZ, 2009).

Em 07 de Outubro de 2005, por meio da Resolução CFC 1.055/05, foi criado o Comitê de Pronunciamentos Contábeis (CPC), cujos objetivos são estudar, preparar e emitir Pronunciamentos Técnicos sobre procedimentos de Contabilidade e a divulgação de informações dessa natureza, para permitir a emissão de normas pela entidade reguladora brasileira, visando centralizar e uniformizar o seu processo de produção, colocando-se sempre em pauta a convergência da Contabilidade Brasileira aos padrões internacionais.

Mais recentemente, a Deliberação CVM 647/2010 trouxe mudanças no que se refere à adoção inicial das Normas Internacionais de Contabilidade, postergando alguns prazos e recomendando algumas conciliações.

$\mathrm{Na}$ opinião de Santos e Calixto (2010), as Normas Internacionais de Contabilidade contrapõem-se à tradição formalista brasileira, pois fundamentadas no direito consuetudinário, priorizam a essência sobre a forma, o julgamento da realidade econômica sobre a mera desincumbência normativa e a transparência para o investidor. Percebe-se, portanto, pela opinião desses autores, que a convergência brasileira não será um processo simples, pois questões que vão além da mera forma legal irão exigir dos contadores e gestores maior discricionariedade para que as demonstrações contábeis representem adequadamente a realidade econômica das organizações.

\subsection{Estudos Recentes sobre o Impacto da Convergência no Value Relevance das Informações Contábeis}

Nos últimos anos, diversos estudos tem se preocupado com modificações na qualidade contábil advindas do processo de convergência contábil internacional. Para medir essa qualidade, utilizam diferenças métricas, sendo as mais comuns o gerenciamento de resultados, a tempestividade no reconhecimento de perdas e medidas de value relevance. 
Uma das maneiras de se medir a utilidade das informações contábeis é por meio de estudos sobre value relevance, que examinam a relação entre os valores do mercado de ações e os números contábeis (BARTH; BEAVER; LANDSMAN, 2001).

No entanto, Alsalman (2003) destaca que a utilidade dos relatórios financeiros não é influenciada somente pela qualidade dos padrões contábeis de cada país, mas também por outros fatores institucionais específicos que afetam a demanda e a oferta de informações financeiras. Ball, Kothari e Robin (2000) e Ball, Robin e Wu (2000) sugerem que fatores como mecanismos de proteção aos investidores, estrutura de propriedade e a qualidade da obrigação legal podem explicar diferenças na utilidade dos números contábeis entre os países.

Alguns pesquisadores têm investigado o efeito de diferentes padrões contábeis no preço das ações (ALFORD et al., 1993; ALI; HWANG, 1997). Hung (2001) analisou empresas de 21 países no período de 1991 a 1997 e seus resultados apontaram que a utilização de accruals contábeis afetava negativamente o value relevance das demonstrações contábeis em países com fracos mecanismos de proteção ao investidor, enquanto que em países com mecanismos de proteção mais fortes esse problema não era observado.

Por sua vez, White (1999) examinou diferenças na informação contábil e características institucionais entre Alemanha e Japão e os Estados Unidos da América (EUA). Seu estudo partiu da premissa de que os sistemas contábeis e os ambientes institucionais de Alemanha e Japão contrastavam com os dos EUA. Sua hipótese consistia na existência de diferenças em como a informação contábil era utilizada na avaliação do patrimônio, ou no value relevance da informação contábil. Seus resultados apontaram que a informação contábil possuía menor value relevance na Alemanha e no Japão em relação aos EUA. Nos dois primeiros países, a contabilidade não está direcionada prioritariamente aos investidores, como é nos EUA, o que justificaria os resultados encontrados.

Alsalman (2003) analisou se padrões contábeis ou fatores institucionais eram determinantes nas diferenças de value relevance nos números contábeis entre os países, mais especificamente, na Arábia Saudita e no Kuwait. Seu estudo partiu do pressuposto de que os proponentes da harmonização contábil internacional concordam que os investidores dão suporte para a necessidade de comparabilidade das informações. No entanto, os oponentes desse processo argumentam que os esforços para se atingir um conjunto comum de padrões contábeis ao redor do mundo podem não alcançar a comparabilidade quanto às diferenças econômicas, culturais e políticas entre os países. Seus resultados apontam que há diferenças significativas no value relevance entre países com o mesmo conjunto de padrões contábeis, mas com diferentes fatores institucionais. Por outro lado, não há diferenças significativas entre países, na maior parte dos casos, no value relevance entre países com diferentes padrões contábeis, mas com ambientes institucionais similares.

Diante desses estudos, depreende-se que a adoção de padrões contábeis diferenciados ou de maior qualidade não é fator determinante para modificações no value relevance das demonstrações contábeis. Ao invés disso, fatores como mecanismos de proteção aos investidores, força do mercado de capitais e fatores institucionais de cada país apresentam influência mais significativa sobre o value relevance das informações contábeis. Assim, elabora-se a primeira hipótese (nula) de pesquisa:

$\mathrm{H}_{0}$ - A adoção de normas contábeis convergentes com as normas do IASB não modifica o value relevance das demonstrações contábeis das empresas brasileiras analisadas.

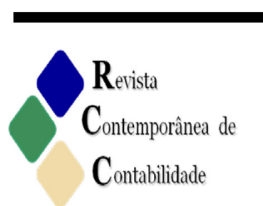

ISSN 2175-8069, UFSC, Florianópolis, v. 11, n. 22, p. 95 -118, jan./abr. 2014 
No entanto, alguns estudos apontam que a adoção das IAS/IFRS aumenta a qualidade da informação contábil divulgada pelas empresas, caracterizada principalmente pela redução dos níveis de gerenciamento de resultados e pelo aumento no value relevance das demonstrações contábeis.

No rol desses estudos, Barth, Landsman e Lang (2008) analisaram 397 empresas de 21 países entre os anos de 1994 e 2003, comparando a qualidade das informações contábeis de empresas que evidenciam sob as normas do $I A S B$ e sob as normas contábeis locais dos países. Os resultados de sua pesquisa indicam que empresas que aplicaram as IASs demonstraram maior value relevance em seus números contábeis.

O estudo de Karampinis e Hevas (2009) analisaram o efeito da adoção obrigatória das IFRS sobre o value relevance dos ganhos e do patrimônio líquido utilizando dados da Bolsa de Valores de Atenas, na Grécia. O país possui sistema legal code law, com normas contábeis locais conservadoras, de forte conformidade fiscal e orientadas para bancos, resultando num efeito negativo do value relevance das demonstrações contábeis. Era esperado que a adoção das IFRS promovesse a contabilidade a valor justo e enfraquecesse o link entre as regras fiscais e contábeis, elevando o value relevance dos ganhos e do patrimônio líquido no país. Os resultados da pesquisa apontaram nessa direção para as demonstrações contábeis consolidadas, com incremento no value relevance sobre os ganhos e o patrimônio líquido.

$\mathrm{Na}$ França, Cormier et al. (2009) examinaram o value relevance dos ajustes patrimoniais obrigatórios e opcionais reconhecidos como resultado da adoção inicial das IFRS por empresas francesas em 2005. Seus resultados apontam para melhoria do value relevance após a primeira adoção, sendo percebido como uma melhoria na qualidade da informação contábil pelas empresas francesas.

Nesta mesma linha de resultados, Iatridis e Rouvolis (2010) também encontraram maior value relevance nas mensurações contábeis com a adoção das IFRS ao analisar 254 empresas gregas entre os anos de 2004 e 2005. O mesmo resultado foi encontrado por Iatridis (2010) ao investigar 241 empregas inglesas listadas na Bolsa de Valores de Londres entre 2004 e 2005.

O estudo de Kousenidis, Ladas e Negakis (2010) examinou o value relevance da informação contábil nos períodos pré e pós-adoção das IFRS por empresas Gregas, entre os anos de 2003 e 2006. Seus resultados apontam que o value relevance do patrimônio líquido em relação ao preço das ações diminuiu após a adoção das IFRS. Esses autores atribuem esse resultado a alta volatilidade do valor do patrimônio líquido nesse período, considerado um período de transição. Por outro lado, o poder explanatório dos lucros sobre o preço das ações aumentou com a adoção das IFRS.

Com base nesses estudos, pode-se supor que a adoção das normas contábeis do IASB resulta em aumento do value relevance das demonstrações contábeis, o que leva a formulação da segunda hipótese (alternativa) da pesquisa:

$\mathrm{H}_{1}$ - A adoção de normas contábeis convergentes com as normas do IASB aumenta o value relevance das demonstrações contábeis das empresas brasileiras analisadas. 


\section{Método e Procedimentos da Pesquisa}

Este estudo pode ser classificado como descritivo. O procedimento utilizado para a coleta dos dados foi a pesquisa documental, a partir de informações coletadas na base de dados Thomson Financial, no sítio da Thomson One Banker (http://banker.thomson.com). A análise dos dados foi realizada por meio de abordagem quantitativa.

\subsection{População e Amostra}

A população de pesquisa consiste em empresas brasileiras listadas na BM\&FBovespa, listadas na base de dados da Thomson Financial. A amostra é não-probabilística, podendo ser classificada como por acessibilidade. Foram consideradas apenas empresas brasileiras que apresentassem informações para todas as variáveis de pesquisa, durante todo o período analisado, que compreendeu os anos de 2006 a 2011, totalizando 118 empresas.

\subsection{Coleta dos Dados}

A fim de avaliar o value relevance das demonstrações contábeis de empresas brasileiras, do período pré-convergência (2006 a 2007) para o período pós-convergência (2010 a 2011) às normas contábeis internacionais, a partir do modelo utilizado por Barth, Landsman e Lang (2008), foram coletadas as seguintes informações:

$\mathrm{P}_{\mathrm{ti}}=$ preço da ação no início do exercício;

$\mathrm{P}_{\mathrm{tf}}=$ preço da ação no final do exercício;

$\mathrm{P}_{\mathrm{t} 1+3}=$ preço da ação no terceiro mês do exercício analisado;

$\mathrm{P}_{\mathrm{t} 2+3}=$ preço da ação três meses após o fechamento do exercício analisado;

$\mathrm{P}_{\mathrm{t} 2+6}=$ preço da ação seis meses após o fechamento do exercício analisado;

BVEPS = valor patrimonial da ação;

NIPS = lucro por ação;

$\mathrm{NI} / \mathrm{P}=$ lucro por ação dividido pelo preço da ação no início do exercício;

RETURN = logaritmo natural do preço da ação três meses após o fechamento do exercício $\left(\mathrm{P}_{\mathrm{t} 2+3}\right)$ dividido pelo preço da ação no terceiro mês do exercício $\left(\mathrm{P}_{\mathrm{t} 1+3}\right)$.

\subsection{Tratamento dos Dados}

A primeira medida de value relevance do modelo utilizado por Barth, Landsman e Lang (2008) está baseada no poder explanatório da regressão do preço da ação sobre o lucro líquido e o valor do patrimônio líquido das empresas. Seguindo os estudos de Lang, Raedy e Yetman (2003) e Lang, Raedy e Wilson (2006), fez-se a regressão do valor da ação, seis meses após o encerramento do exercício $\left(\mathrm{P}_{\mathrm{t} 2+6}\right)$, com o valor patrimonial da ação (BVEPS) e com o lucro por ação (NIPS), separando a análise em três períodos: pré-convergência (2006 a 2007), período de implantação das IFRS (2008 a 2009) e período pós-convergência (2010 a 2011). A primeira métrica de value relevance consiste no valor do $R^{2}$ ajustado da regressão dada pela equação 1 :

$$
P_{t 2+6}=\beta_{0}+\beta_{1} B_{V E P S}+\beta_{2} N I P S_{i t}+\varepsilon_{i t}
$$

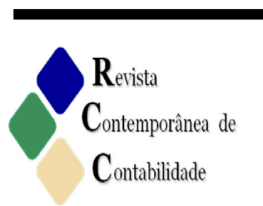

ISSN 2175-8069, UFSC, Florianópolis, v. 11, n. 22, p. 95 -118, jan./abr. 2014 
Essa primeira medida de value relevance pretende analisar se após o processo de convergência às normas contábeis internacionais, o valor de mercado da ação está mais alinhado com o valor do patrimônio líquido e do lucro evidenciados pelas empresas. Caso isso ocorra, infere-se que as demonstrações contábeis convergentes com as normas contábeis internacionais refletem melhor a realidade econômica e financeira das empresas, sendo reconhecido pelos investidores do mercado.

Além da equação 1, uma segunda foi utilizada, alterando-se a variável dependente do modelo. Ao invés do preço da ação seis meses após o encerramento do exercício $\left(\mathrm{P}_{\mathrm{t} 2+6}\right)$, utilizou-se o preço de fechamento do exercício $\left(\mathrm{P}_{\mathrm{tf}}\right)$, a fim de comparar o valor do PL e do lucro por ação com o preço de mercado da ação no mesmo período (final do exercício).

$$
P_{t f}=\beta_{0}+\beta_{1} B V E P S_{i t}+\beta_{2} N I P S_{i t}+\varepsilon_{i t}
$$

A segunda métrica de value relevance do modelo utilizado por Barth, Landsman e Lang (2008) refere-se ao poder explanatório do lucro líquido por ação (NIPS) sobre o retorno anual da ação (RETURN). Ela é formada pelo valor ajustado do $\mathrm{R}^{2}$ da regressão dada pela equação 3, que contempla o lucro por ação divido pelo preço da ação no início do exercício (NI/P) como variável dependente e logaritmo natural do preço da ação três meses após o fechamento do exercício $\left(\mathrm{P}_{\mathrm{t} 2+3}\right)$, dividido pelo preço da ação no terceiro mês do exercício $\left(\mathrm{P}_{\mathrm{t} 1+3}\right)(\mathrm{RETURN})$ como variável independente:

$$
N I / P_{i t}=\beta_{0}+\beta_{1} R E T U R N+\varepsilon_{i t}
$$

Assim como a primeira equação, essa segunda medida busca identificar se após o processo de convergência às normas contábeis do IASB, o retorno da ação no mercado está relacionado ao lucro por ação evidenciado pela empresa. Quanto maior essa relação, maior a qualidade da informação contábil divulgada pela empresa. Havendo aumento nessa relação do período pré-IFRS para o período pós-IFRS, significa que o objetivo da convergência, que é a melhoria da informação divulgada aos usuários, está sendo alcançado.

Mais três equações foram adicionadas ao modelo utilizado por Barth, Landsman e Lang (2008). Para verificar se as duas métricas de value relevance apresentam diferenças significativas entre os dois períodos analisados (2006 a 2011), incluiu-se nas equações 1 a 3 duas variáveis dummies (dummy_1 e dummy_2). Segundo Fávero et al. (2009), quando o número de categorias de uma variável qualitativa é maior do que 2, são necessárias (n-1) dummies. Nesse estudo, considerando que a variável qualitativa "período" possui 3 categorias: pré-IFRS (2006 a 2007); período de implantação das IFRS (2008 a 2009); e período pós-IFRS (2010-2011), utilizou-se então as duas variáveis dummies (dummy_l e dummy_2) da seguinte forma:

Quadro 1 - Variáveis dummies

\begin{tabular}{l|c|c}
\hline \multicolumn{1}{c|}{ Período } & Dummy_1 & Dummy_2 \\
\hline Pré-IFRS (2006 a 2007) & 0 & 0 \\
\hline Implantação (2008 a 2009) & 1 & 0 \\
\hline Pós-IFRS (2010 a 2011) & 0 & 1 \\
\hline
\end{tabular}

Fonte: Elaborada pelos autores. 
Com isso, três novas equações foram testadas:

$$
\begin{aligned}
& P_{t 2+6}=\beta_{0}+\beta_{1} \text { BVEPS }_{i t}+\beta_{2} \text { NIPS }_{i t}+\beta_{3} \text { Dummy }_{-} 1+\beta_{4} \text { Dummy }_{-} 2+\varepsilon_{i t} \\
& P_{t f}=\beta_{0}+\beta_{1} \text { BVEPS }_{i t}+\beta_{2} \text { NIPS }_{i t}+\beta_{3} \text { Dummy }_{-} 1+\beta_{4} \text { Dummy_ } 2+\varepsilon_{i t} \\
& N I / P_{i t}=\beta_{0}+\beta_{1} \text { RETURN }+\beta_{2} \text { Dummy_ } 1+\beta_{3} \text { Dummy_ } 2+\varepsilon_{i t}
\end{aligned}
$$

Mediante as equações, caso o coeficiente das variáveis dummies seja significativo, depreende-se que há diferenças significativas nas medidas de value relevance entre os períodos analisados.

\section{Apresentação e Análise dos Resultados}

Antes de apresentar os resultados das medidas de value relevance, apresenta-se na

\begin{tabular}{|c|c|c|c|c|c|c|c|c|c|}
\hline \multirow[b]{2}{*}{ Variáveis } & \multicolumn{3}{|c|}{ Período Pré-convergência } & \multicolumn{3}{|c|}{ Período de Implantação } & \multicolumn{3}{|c|}{ Período Pós-convergência } \\
\hline & Média & Mediana & $\begin{array}{l}\text { Desvio- } \\
\text { padrão }\end{array}$ & Média & Mediana & $\begin{array}{l}\text { Desvio- } \\
\text { padrão }\end{array}$ & Média & Mediana & $\begin{array}{l}\text { Desvio- } \\
\text { padrão }\end{array}$ \\
\hline $\mathrm{P}_{\mathrm{ti}}$ & 4,382 & 0,010 & 23,184 & 1,422 & 0,010 & 14,704 & 0,089 & 0,010 & 0,951 \\
\hline $\mathrm{P}_{\mathrm{tf}}$ & 4,151 & 0,010 & 26,407 & 0,133 & 0,010 & 1,235 & 0,025 & 0,010 & 0,070 \\
\hline $\mathrm{P}_{\mathrm{t} 1+3}$ & 4,535 & 0,010 & 22,247 & 1,653 & 0,010 & 17,930 & 0,082 & 0,010 & 0,825 \\
\hline $\mathrm{P}_{\mathrm{t} 2+3}$ & 4,210 & 0,010 & 26,543 & 0,135 & 0,010 & 1,225 & 0,026 & 0,010 & 0,070 \\
\hline $\mathrm{P}_{\mathrm{t} 2+6}$ & 4,987 & 0,020 & 39,627 & 0,127 & 0,010 & 1,153 & 0,024 & 0,010 & 0,058 \\
\hline BVEPS & 2,606 & 0,010 & 16,853 & 0,138 & 0,010 & 1,325 & 0,022 & 0,010 & 0,065 \\
\hline NIPS & 0,242 & 0,001 & 2,184 & 0,024 & 0,001 & 0,249 & 0,003 & 0,001 & 0,008 \\
\hline $\mathrm{NI} / \mathrm{P}$ & 0,045 & 0,000 & 0,159 & 0,068 & 0,014 & 0,142 & 0,073 & 0,057 & 0,170 \\
\hline RETURN & $-0,415$ & 0,000 & 1,704 & $-0,142$ & 0,000 & 1,154 & $-0,027$ & 0,000 & 0,550 \\
\hline
\end{tabular}
Tabela 1 a estatística descritiva das variáveis utilizadas no estudo.

Tabela 1 - Estatística descritiva das variáveis

$\mathrm{P}_{\mathrm{ti}}=$ preço da ação no início do exercício

$\mathrm{P}_{\mathrm{tf}}=$ preço da ação no final do exercício;

$\mathrm{P}_{\mathrm{t} 1+3}=$ preço da ação no terceiro mês do exercício analisado;

$\mathrm{P}_{\mathrm{t}_{2}+3}=$ preço da ação três meses após o fechamento do exercício analisado;

$\mathrm{P}_{\mathrm{t} 2+6}=$ preço da ação seis meses após o fechamento do exercício analisado;

BVEPS = valor patrimonial da ação;

NIPS = lucro por ação;

$\mathrm{NI} / \mathrm{P}=$ lucro por ação divido pelo preço da ação no início do exercício;

RETURN = logaritmo natural do preço da ação três meses após o fechamento do exercício $\left(\mathrm{P}_{\mathrm{t} 2+3}\right)$ divido pelo preço da ação no terceiro mês do exercício $\left(\mathrm{P}_{\mathrm{t} 1+3}\right)$.

Fonte: Dados da pesquisa.

A Tabela 1 demonstra que o preço das ações no período pré-convergência sofreu variações significativas, quando comparados os valores entre as empresas, resultando num desvio-padrão elevado. Tal fato pode estar relacionado à instabilidade econômica no período de análise, o que pode ter provocado aumentos e ou diminuições significativas nos valores das ações de algumas empresas.

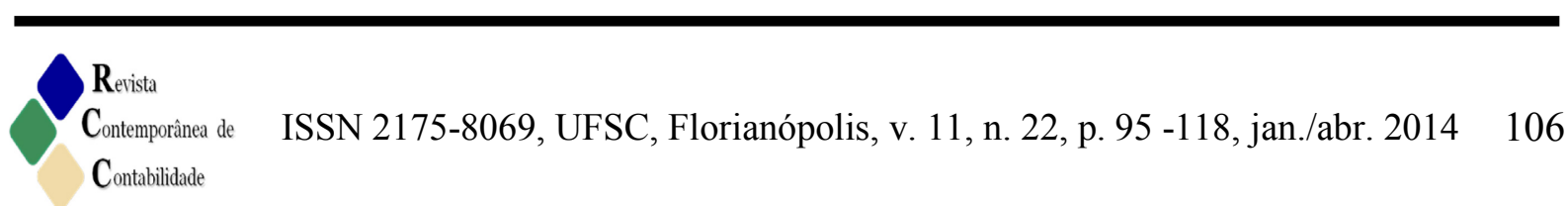


Ao observar a mediana dos preços das ações, nota-se que são semelhantes em todos os períodos. Dessa forma, pode-se supor que haviam empresas que apresentavam valor elevado de suas ações no período pré-convergência, elevando a média e o desvio-padrão desses dados. Nos períodos de implantação e de pós-convergência esses valores foram reduzidos, diminuindo respectivamente, a média e o desvio-padrão do valor das ações. $O$ valor patrimonial das ações (BVEPS) e o lucro por ação (NIPS) também apresentaram o mesmo declínio, indicando uma possível relação entre essas variáveis. Nas outras variáveis de análise (NI/P e RETURN) não foram observadas variações significativas nos três períodos.

Os resultados da primeira medida de value relevance do modelo utilizado por Barth, Landsman e Lang (2008), baseada no poder explanatório da regressão do preço da ação sobre o lucro líquido e o valor do patrimônio líquido das empresas, estão apresentados na Tabela 2:

Tabela 2 - Primeira medida de value relevance das demonstrações contábeis

\begin{tabular}{l|c|c|c|c|c}
\hline $\begin{array}{c}\text { Variável } \\
\text { dependente }\end{array}$ & $\begin{array}{c}\text { Variáveis } \\
\text { independentes }\end{array}$ & Período & $\mathbf{R}^{2}$ & Estatística F & Sig. \\
\hline \multirow{2}{*}{$\mathrm{P}_{\mathrm{t} 2+6}$} & LnBVEPS & Pré-convergência & 0,212 & 15,258 & 0,000 \\
\cline { 2 - 6 } & LnNIPS & Implantação & 0,594 & 85,022 & 0,000 \\
\cline { 2 - 6 } & & Pós-convergência & 0,362 & 43,215 & 0,000 \\
\hline
\end{tabular}

$\mathrm{P}_{\mathrm{t} 2+6}=$ preço da ação seis meses após o fechamento do exercício analisado;

LnBVEPS = logaritmo do valor patrimonial da ação;

LnNIPS = logaritmo do lucro por ação.

Fonte: Dados da pesquisa.

Considerando que as variáveis BVEPS e NIPS apresentam coeficiente de correlação elevado, tais variáveis foram transformadas pelos seus logaritmos, seguindo sugestão de Cunha e Coelho (2009), para eliminar os problemas de multicolinearidade. A primeira medida de value relevance, com base no preço das ações, apresentou significância estatística nos três períodos de análise (sig. $<0,05)$. No entanto, constatou-se um aumento no poder explicativo $\left(\mathrm{R}^{2}\right)$ do modelo no período de implantação (2008/2009), o que pode indicar uma elevação no value relevance da informação contábil nesse período, com maior relação entre o valor patrimonial da ação (BVEPS) e o lucro por ação (NIPS) com o preço das ações.

No entanto, esse resultado pode ter sido influenciado pela queda significativa, tanto no preço das ações, como no BVEPS e no NIPS, do período pré-convergência para o período de implantação, observado na Tabela 1.

Dessa forma, uma segunda equação foi testada procurando identificar a relação entre o valor patrimonial da ação (BVEPS) e o lucro por ação (NIPS) com o preço das ações. No entanto, nesta segunda equação, ao invés de testar essas variáveis com o preço da ação seis meses após o encerramento do exercício $\left(\mathrm{P}_{\mathrm{t} 2+6}\right)$, utilizou-se o valor da ação no final do exercício $\left(\mathrm{P}_{\mathrm{tf}}\right)$.

A Tabela 3 apresenta relação semelhante entre o valor patrimonial da ação e o lucro por ação com o preço da ação ao observado na Tabela 2 , com aumento no $\mathrm{R}^{2}$ do período préconvergência para o período de implantação e posterior queda no período pós-convergência.

Depreende-se do exposto que a utilização do preço da ação seis meses após o encerramento do exercício $\left(\mathrm{P}_{\mathrm{t} 2+6}\right)$ ou do preço no final do exercício $\left(\mathrm{P}_{\mathrm{tf}}\right)$ não alterou de modo significativo o coeficiente de determinação $\left(\mathrm{R}^{2}\right)$ encontrado. 
Tabela 3 - Segunda medida de value relevance das demonstrações contábeis

\begin{tabular}{l|c|c|c|c|c}
\hline $\begin{array}{c}\text { Variável } \\
\text { dependente }\end{array}$ & $\begin{array}{c}\text { Variáveis } \\
\text { independentes }\end{array}$ & Período & $\mathbf{R}^{\mathbf{2}}$ & $\begin{array}{c}\text { Estatística } \\
\text { F }\end{array}$ & Sig. \\
\hline \multirow{2}{*}{$\mathrm{P}_{\mathrm{tf}}$} & LnBVEPS & Pré-convergência & 0,289 & 22,581 & 0,000 \\
\cline { 3 - 6 } & LnNIPS & Implantação & 0,581 & 80,768 & 0,000 \\
\cline { 3 - 6 } & & Pós-convergência & 0,320 & 36,092 & 0,000 \\
\hline
\end{tabular}

$\mathrm{P}_{\mathrm{tf}}=$ preço da ação no final do exercício;

LnBVEPS = logaritmo do valor patrimonial da ação;

LnNIPS = logaritmo do lucro por ação.

Fonte: Dados da pesquisa.

Tanto a equação 1 (Tabela 2) quanto a equação 2 (Tabela 3 ) apresentam coeficientes significativos $($ sig. $<0,05)$ nos três período analisados, sendo que o período de implantação das normas é o que apresenta maior relação entre o preço da ação e o valor patrimonial e o lucro por ação.

Com base nesses resultados, pode-se afirmar que há indícios de aumento no value relevance da informação contábil do período pré-convergência para o período de implantação das normas convergentes com as normas contábeis internacionais nas empresas analisadas.

Para testar a significância das diferenças encontradas no $\mathrm{R}^{2}$ entre os períodos, foram calculados os resíduos de cada regressão para cada caso, comparando-se o valor predito com o valor informado do preço da ação seis meses após o encerramento do exercício $\left(\mathrm{P}_{\mathrm{t} 2+6}\right)$ e do preço da ação no final do exercício $\left(\mathrm{P}_{\mathrm{tf}}\right)$. $\mathrm{Na}$ sequência, aplicou-se o Teste $\mathrm{F}$ para duas variâncias de amostras diferentes, a fim de observar se os resíduos encontrados eram diferentes. Quanto menor o resíduo encontrado, pressupõe-se que maior será o poder explicativo das variáveis independentes do modelo. Logo, maior o value relevance da informação contábil. Os testes estão apresentados na Tabela 4 a seguir.

Tabela 4 - Teste F para variâncias dos modelos entre os períodos

\begin{tabular}{|c|c|c|c|c|c|c|}
\hline & \multicolumn{2}{|c|}{$\begin{array}{l}\text { pré-convergência } \\
\text { versus implantação }\end{array}$} & \multicolumn{2}{|c|}{$\begin{array}{l}\text { implantação versus } \\
\text { pós-convergência }\end{array}$} & \multicolumn{2}{|c|}{$\begin{array}{l}\text { pré versus pós- } \\
\text { convergência }\end{array}$} \\
\hline & $\mathrm{Pt} 2+6$ & Ptf & $\mathrm{Pt} 2+6$ & Ptf & $\mathrm{Pt} 2+6$ & Ptf \\
\hline Estatística F & 17765,983 & 22265,614 & 3,367 & 1,010 & 59824,487 & 22481,161 \\
\hline Graus de liberdade (Numerador) & 235 & 235 & 235 & 235 & 235 & 235 \\
\hline Graus de liberdade (Denominador) & 235 & 235 & 235 & 235 & 235 & 235 \\
\hline P-Valor & 0,000 & 0,000 & 0,000 & 0,941 & 0,000 & 0,000 \\
\hline Desvio padrão amostral (Amostra1) & 8,504 & 6,432 & 0,064 & 0,043 & 8,504 & 6,432 \\
\hline Desvio padrão amostral (Amostra2) & 0,064 & 0,043 & 0,035 & 0,043 & 0,035 & 0,043 \\
\hline $\begin{array}{l}\text { Intervalo de Confiança para razão } \\
\text { das Variâncias }\end{array}$ & $95 \%$ & $95 \%$ & $95 \%$ & $95 \%$ & $95 \%$ & $95 \%$ \\
\hline Limite Inferior & 13748,865 & 17231,071 & 2,606 & 0,781 & 46297,398 & 17397,881 \\
\hline Limite Superior & 22956,816 & 28771,140 & 4,351 & 1,305 & 77303,895 & 29049,666 \\
\hline
\end{tabular}

Fonte: Dados da pesquisa.

A Tabela 4 apresenta variações significativas entre os resíduos dos dois modelos testados $\left(\mathrm{P}_{\mathrm{t} 2+6} \quad \mathrm{e} \quad \mathrm{P}_{\mathrm{tf}}\right)$, comparando-se os períodos pré-convergência versus período de implantação e pré-convergência versus pós-convergência. Já ao comparar o período de implantação com o período pós-convergência, apenas para a variável $\mathrm{P}_{\mathrm{t} 2+6}$ foi encontrada diferença significativa.

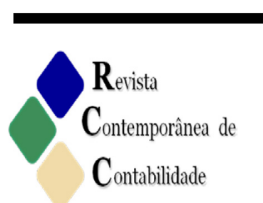

ISSN 2175-8069, UFSC, Florianópolis, v. 11, n. 22, p. 95 -118, jan./abr. 2014 
A terceira medida de value relevance do modelo utilizado por Barth, Landsman e Lang (2008), baseada no poder explanatório da regressão do lucro por ação dividido pelo preço da ação no início do exercício $(\mathrm{NI} / \mathrm{P})$, em relação ao do preço da ação três meses após o fechamento do exercício $\left(\mathrm{P}_{\mathrm{t} 2+3}\right)$ divido pelo preço da ação no terceiro mês do exercício $\left(\mathrm{P}_{\mathrm{t} 1+3}\right)$ (RETURN), está apresentada na Tabela 5.

Tabela 5 - Terceira medida de value relevance das demonstrações contábeis

\begin{tabular}{l|c|c|c|c|c}
\hline \multirow{2}{*}{$\begin{array}{c}\text { Variável } \\
\text { dependente }\end{array}$} & $\begin{array}{c}\text { Variável } \\
\text { independente }\end{array}$ & Período & $\mathbf{R}^{2}$ & Estatística F & Sig. \\
\hline \multirow{2}{*}{$\mathrm{NI} / \mathrm{P}_{\mathrm{it}}$} & \multirow{2}{*}{ RETURN $_{\mathrm{it}}$} & Pré-convergência & 0,012 & 3,947 & 0,048 \\
\cline { 3 - 6 } & & Implantação & 0,022 & 6,165 & 0,014 \\
\cline { 3 - 6 } & & Pós-convergência & 0,011 & 3,572 & 0,060 \\
\hline
\end{tabular}

$\mathrm{NI} / \mathrm{P}=$ lucro por ação divido pelo preço da ação no início do exercício;

RETURN $=$ logaritmo natural do preço da ação três meses após o fechamento do exercício $\left(\mathrm{P}_{\mathrm{t} 2+3}\right)$ divido pelo preço da ação no terceiro mês do exercício $\left(\mathrm{P}_{\mathrm{t} 1+3}\right)$.

Fonte: Dados da pesquisa.

Observa-se na Tabela 5 que a segunda medida de value relevance não apresentou coeficiente significativo (sig. $>0,05$ ) no período pós-convergência. Mesmo apresentando significância nos dois períodos anteriores, o coeficiente de determinação dos três períodos é muito baixo, variando de $1 \%$ a $2 \%$. Portanto, com base nessa medida, não se pode afirmar que houve aumento de value relevance da informação contábil a partir da convergência às normas contábeis internacionais. A fim de verificar se as três métricas de value relevance utilizadas apresentam diferenças significativas entre os três períodos verificados (pré-convergência, implantação e pós-convergência), aplicou-se as equações 4 a 6 , com a inclusão de duas variáveis dummy (Dummy_1 e Dummy_2), conforme apresentado no Quadro 1 anteriormente.

As regressões apresentadas nas Tabelas 6, 7 e 8 apresentaram problemas relacionados ao não atendimento do pressuposto da homocedasticidade. Para solucionar o problema, foi aplicada a correção de White. Além disso, como as variáveis BVEPS e NIPS eram altamente correlacionadas, optou-se por excluir uma dessas variáveis, no caso, a variável NIPS, que apresentou menor por explicativo no modelo em relação à variável BVEPS.

Tabela 6 - Análise do período sobre a primeira medida de value relevance das demonstrações contábeis

\begin{tabular}{|c|c|c|c|c|c|c|c|}
\hline \multirow[t]{2}{*}{ Modelo } & & \multicolumn{2}{|c|}{$\begin{array}{l}\text { Coeficientes não } \\
\text { padronizados }\end{array}$} & \multirow[t]{2}{*}{$\mathrm{T}$} & \multirow[t]{2}{*}{ Sig. } & \multicolumn{2}{|c|}{ CollinearityStatistics } \\
\hline & & $\mathrm{B}$ & Erro padrão & & & Tolerance & VIF \\
\hline \multirow[t]{7}{*}{1} & (Constant) & $-0,968$ & 0,339 & $-2,859$ & 0,004 & & \\
\hline & BVEPS & 2,285 & 0,020 & 115,217 & $0,000 *$ & 0,985 & 1,015 \\
\hline & Dummy_1 & 0,780 & 0,476 & 1,640 & $0,101 * *$ & 0,742 & 1,348 \\
\hline & Dummy_2 & 0,941 & 0,476 & 1,976 & $0,048^{*}$ & 0,741 & 1,349 \\
\hline & \multicolumn{2}{|l|}{$\mathrm{R}^{2}$} & 0,950 & \multicolumn{2}{|l|}{ Estatística F } & \multicolumn{2}{|r|}{4472,882} \\
\hline & \multicolumn{2}{|l|}{$\mathrm{R}^{2}$ ajustado } & 0,950 & \multicolumn{2}{|l|}{ Sig. F } & \multicolumn{2}{|r|}{0,000} \\
\hline & \multicolumn{2}{|c|}{ Erro padrão da regressão } & 5,140 & \multicolumn{2}{|c|}{ Durbin-Watson } & \multicolumn{2}{|r|}{1,914} \\
\hline
\end{tabular}

* significativo ao nível de 5\%

** significativo ao nível de $10 \%$

Variável dependente: $\mathrm{P}_{\mathrm{t} 2+6}=$ preço da ação seis meses após o fechamento do exercício analisado;

BVEPS $=$ valor patrimonial da ação;

Dummies 1 e 2 = período de análise (0;0 pré-convergência; 1;0 implantação; $0 ; 1$ pós-convergência)

Fonte: Dados da pesquisa. 
A Tabela 6 demonstra que os coeficientes das variáveis dummies foram significativos a $10 \%$ e a $5 \%$, respectivamente, indicando que os três períodos analisados apresentam influência na relação entre o BVEPS e o preço de mercado da ação. Tal resultado corrobora com o encontrado na Tabela 2, que aponta um $\mathrm{R}^{2}$ mais elevado para os valores do período de implantação do processo de convergência, além dos resultados do Teste $F$ apresentados na Tabela 4. A mesma análise foi realizada para a segunda medida de value relevance, apresentada na Tabela 7.

Tabela 7 - Análise do período sobre a segunda medida de value relevance das demonstrações contábeis

\begin{tabular}{|c|c|c|c|c|c|c|c|}
\hline \multirow[t]{2}{*}{ Modelo } & & \multicolumn{2}{|c|}{$\begin{array}{c}\text { Coeficientes não } \\
\text { padronizados }\end{array}$} & \multirow[t]{2}{*}{$\bar{T}$} & \multirow[t]{2}{*}{ Sig. } & \multicolumn{2}{|c|}{ CollinearityStatistics } \\
\hline & & $\mathrm{B}$ & Erro padrão & & & Tolerance & VIF \\
\hline \multirow[t]{7}{*}{1} & (Constant) & 0,216 & 0,261 & 0,825 & 0,410 & & \\
\hline & BVEPS & 1,510 & 0,015 & 98,615 & $0,000 *$ & 0,985 & 1,015 \\
\hline & Dummy_1 & $-0,290$ & 0,367 & $-0,791$ & 0,429 & 0,742 & 1,348 \\
\hline & Dummy_2 & $-0,225$ & 0,367 & $-0,612$ & 0,541 & 0,741 & 1,349 \\
\hline & \multicolumn{2}{|l|}{$\mathrm{R}^{2}$} & 0,934 & \multicolumn{2}{|l|}{ Estatística F } & \multicolumn{2}{|r|}{3296,864} \\
\hline & \multicolumn{2}{|l|}{$\mathrm{R}^{2}$ ajustado } & 0,933 & \multicolumn{2}{|c|}{ Sig. F } & \multicolumn{2}{|r|}{0,000} \\
\hline & \multicolumn{2}{|c|}{ Erro padrão da regressão } & 3,968 & \multicolumn{2}{|c|}{ Durbin-Watson } & \multicolumn{2}{|r|}{2,280} \\
\hline
\end{tabular}

* significativo ao nível de 5\%

Variável dependente: $\mathrm{P}_{\mathrm{tf}}=$ preço da ação no final do exercício;

BVEPS = valor patrimonial da ação;

Dummies 1 e 2 = período de análise ( $0 ; 0$ pré-convergência; $1 ; 0$ implantação; $0 ; 1$ pós-convergência)

Fonte: Dados da pesquisa.

$\mathrm{Na}$ Tabela 7 foi realizada a mesma regressão apresentada na Tabela 6. No entanto, foi alterada a variável dependente, ao invés do preço da ação seis meses após o encerramento do exercício $\left(\mathrm{P}_{\mathrm{t} 2+6}\right)$, foi utilizado o preço da ação ao final do exercício, conforme a equação 2 do Modelo de Barth, Landsman e Lang (2008), já testada na Tabela 2 anteriormente. Trata-se de uma análise adicional à equação 4, apresentada na Tabela 6 .

Ao contrário do observado na Tabela 6 , as variáveis dummies não apresentaram significância nesta regressão, indicando que o período de análise não exerce influência na explicação para o preço das ações ao final do exercício.

$\mathrm{Na}$ Tabela 4 o preço da ação no final exercício também não apresentou coeficiente significativo quando da comparação dos resíduos entre os períodos de implantação e pósconvergência, o que pode indicar menor sensibilidade dessa variável $\left(\mathrm{P}_{\mathrm{tf}}\right)$ ao modelo utilizado no estudo.

O teste de influência do período verificado sobre a terceira medida de value relevance utilizada no estudo é apresentado na Tabela 8 , incluindo-se como variáveis independentes as duas dummies.

Da mesma foram que o constatado na Tabela 7, a Tabela 8 demonstra que as variáveis dummies não apresentaram coeficiente significativo (sig. $>0,05$ ), indicando, portanto, não haver influência do período observado em relação à terceira medida de value relevance empregada no estudo. Além disso, o próprio modelo de regressão não se mostrou significativo, prejudicando qualquer inferência sobre seus resultados.

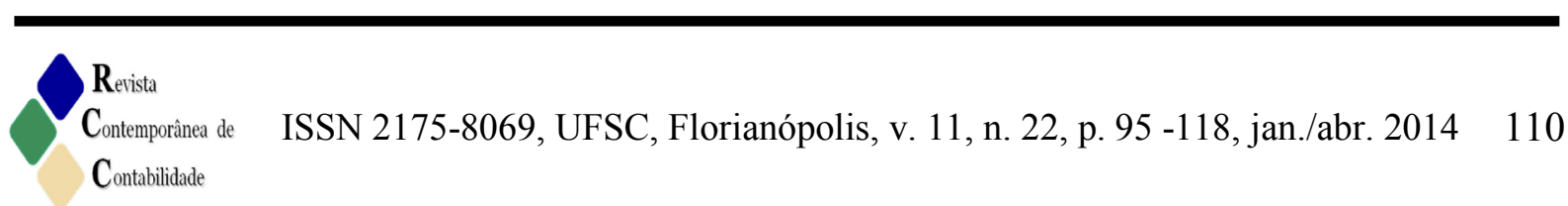


Efeitos do processo de convergência às normas internacionais de contabilidade no value relevance das...

Tabela 8 - Análise do período sobre a terceira medida de value relevance das demonstrações contábeis

\begin{tabular}{l|l|r|r|r|r|r|r}
\hline Modelo & & \multicolumn{2}{|c|}{$\begin{array}{c}\text { Coeficientes não } \\
\text { padronizados }\end{array}$} & \multicolumn{1}{c|}{ T } & \multicolumn{2}{c|}{ Sig. } & \multicolumn{2}{c}{ CollinearityStatistics } \\
& & \multicolumn{1}{l|}{ B } & Erro padrão & & & Tolerance & VIF \\
\hline & & 0,067 & 0,011 & 6,302 & 0,000 & & \\
\hline 1 & (Constant) & 0,008 & 0,003 & 2,675 & 0,008 & 0,983 & 1,018 \\
\hline & RETURN & 0,001 & 0,014 & 0,109 & 0,913 & 0,744 & 1,344 \\
\hline & Dummy_1 & 0,013 & 0,014 & 0,944 & 0,346 & 0,738 & 1,356 \\
\hline & Dummy_2 & 0,009 & Estatística F & & & 2,039 \\
\hline & $\mathrm{R}^{2}$ & 0,004 & Sig. F & & & 0,107 \\
\hline & $\mathrm{R}^{2}$ ajustado & 0,148 & Durbin-Watson & & 1,998 \\
\hline
\end{tabular}

Fonte: Dados da pesquisa.

De maneira geral, os resultados aqui apresentados apontam aumento no $\mathrm{R}^{2}$ da equação 1 (Tabela 2) e da equação 2 (Tabela 3) do período pré-convergência (2006/2007) para o período de implantação das normas (2008/2009), com queda no coeficiente no período pósconvergência (2010/2011). Ao se comparar os resíduos dessas duas equações entre os períodos de análise (Tabela 4), verifica-se que há diferenças significativas em todos os casos, com exceção do $\mathrm{P}_{\mathrm{tf}}$ do período de implantação para o período pós-convergência. Na verificação complementar, considerando os dados de todos os períodos e incluindo variáveis dummies para tratar o efeito de cada período de análise nos resultados, foram encontradas evidências de influência desses períodos nos resultados em relação ao $\mathrm{P}_{\mathrm{t} 2+6}$.

Apesar de algumas pesquisas apontarem que a qualidade dos relatórios financeiros não é influenciada exclusivamente pelo padrão contábil adotado (WHITE, 1999; HUNG, 2001; BALL; KOTHARI; ROBIN, 2000; BALL; ROBIN; WU, 2000; ALSALMAN, 2003), os resultados deste estudo corroboram os de Barth, Landsman e Lang (2008), Karampinis e Hevas (2009), Cormier et al. (2009), Iatridis e Rouvolis (2010) e Kousenidis, Ladas e Negakis (2010), que destacam a influência da convergência às normas contábeis internacionais no aumento do value relevance das informações contábeis.

No entanto, é importante destacar que outros fatores, como o ambiente institucional do país (WHITE, 1999), mecanismos de proteção ao investidor (BALL; KOTHARI; ROBIN, 2000; BALL; ROBIN; WU, 2000; HUNG, 2001) e estrutura de propriedade e a qualidade da obrigação legal (BALL; KOTHARI; ROBIN, 2000; BALL; ROBIN; WU, 2000) podem explicar diferenças na utilidade dos números contábeis entre os países, o que pode ajudar a justificar, inclusive, os resultados contraditórios observados entre os estudos.

Cabe frisar ainda que as empresas brasileiras investigadas estão inseridas em um contexto de sistema legal fundamentado no code law, com forte interferência de regras fiscais na contabilidade antes da convergência, semelhantes às empresas gregas (KARAMPINIS; HEVAS, 2009; IATRIDIS; ROUVOLIS, 2010; KOUSENIDIS; LADAS; NEGAKIS, 2010) e francesas (CORMIER et al., 2009), cujos resultados são semelhantes ao deste estudo.

Por outro lado, em países como Alemanha e Japão (WHITE, 1999) e Arábia Saudita e Kuwait (ALSALMAN, 2003) não há evidências de melhoria do value relevance após a convergência. Depreende-se então que tais países podem apresentar outras características contextuais que podem estar interferindo na melhoria da qualidade da informação contábil divulgadas pelas empresas desses países.

111 ISSN 2175-8069, UFSC, Florianópolis, v. 11, n. 22, p. 95 -118, jan./abr. 2014 


\section{Considerações Finais}

O objetivo deste estudo foi identificar se o processo de convergência às normas contábeis internacionais impactou o value relevance das informações contábeis evidenciadas por companhias brasileiras.

Com a utilização do modelo de Barth, Landsman e Lang (2008), fundamentado em duas equações de regressão linear, contemplando variáveis relacionadas ao preço de mercado das ações, ao valor patrimonial das ações e ao lucro por ação, além da inclusão de uma terceira equação, representando uma alternativa de observação à primeira equação, algumas considerações podem ser apresentadas a respeito do estudo.

A primeira consideração se refere ao comportamento do preço das ações no período pré-convergência, que apresentou elevado desvio-padrão para todos os preços coletados, o que não foi observado nos períodos seguintes. Além disso, constatou-se também queda no preço médio das ações, do período pré-convergência para os demais, o que pode representar um efeito da crise econômica mundial. Essa queda também foi observada no valor patrimonial e no lucro por ação das empresas pesquisadas. Esses fatos podem ter influenciado os resultados das equações, contribuindo para a diferença observada no $\mathrm{R}^{2}$ entre os períodos de análise, constituindo-se, assim, numa limitação da pesquisa.

No entanto, essa limitação poderia afetar de modo mais preponderante a primeira equação, que tem como variável dependente o preço da ação seis meses após o fechamento do exercício. Já as variáveis utilizadas na terceira equação (VI/P e RETURN) não apresentaram diferenças significativas quanto à estatística descritiva entre os períodos observados.

Ao checar a significância dessas diferenças encontradas nas três equações de regressão, entre os períodos observados, constatou-se valores estatisticamente significativos para o preço da ação seis meses após o encerramento do exercício $\left(\mathrm{P}_{\mathrm{t} 2+6}\right)$ em todos os períodos, tanto pelo Teste $\mathrm{F}$ como pela análise de regressão. Para o preço da ação no final do exercício $\left(\mathrm{P}_{\mathrm{tf}}\right)$, o Teste $\mathrm{F}$ indicou diferenças significativas apenas entre os períodos préconvergência e implantação e entre os períodos pré e pós-convergência. Já as variáveis dummies incluídas na regressão não se mostraram significativas. A equação 3 não apresentou coeficientes significativos em nenhum período.

Com base nisso, aceita-se parcialmente a $\mathrm{H}_{1}$, pois os resultados aqui apresentados não possibilitam a rejeição total da $\mathrm{H}_{1}$, nem a aceitação total da $\mathrm{H}_{0}$.

Conclui-se, portanto, que há evidências estatísticas sobre o efeito do processo de convergência contábil internacional no value relevance das demonstrações contábeis das empresas brasileiras pesquisadas, principalmente em relação ao poder explicativo do valor patrimonial da ação (BVEPS) e do lucro por ação (NIPS) sobre o valor de mercado da ação seis meses após o encerramento do exercício $\left(\mathrm{P}_{\mathrm{t} 2+6}\right)$.

Por outro lado, conclui-se também que tal efeito não é observado quando utilizado o preço da ação no final do exercício $\left(\mathrm{P}_{\mathrm{tf}}\right)$ como variável dependente do modelo, nem quando quanto relacionado o retorno anual da ação (RETURN) com o lucro por ação divido pelo preço da ação no início do exercício (NI/P).

Portanto, os resultados encontrados neste estudo sobre os efeitos do processo de convergência contábil internacional no value relevance da informação contábil são contraditórios, dependendo do modelo de análise utilizado. É possível que fatores como mecanismos de proteção aos investidores, força do mercado de capitais e fatores institucionais

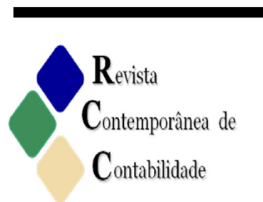

ISSN 2175-8069, UFSC, Florianópolis, v. 11, n. 22, p. 95 -118, jan./abr. 2014 
do país também exerçam influência sobre o value relevance das informações contábeis, como apontado por Ball, Kothari e Robin (2000), Ball, Robin e Wu (2000), Hung (2001) e Alsalman (2003).

Como esse processo ainda está numa fase inicial no Brasil, novos estudos devem ser realizados, com a inclusão de um período maior de análise, o que somente será possível daqui há algum tempo. Nesse caso, outros modelos para apuração do value relevance da informação contábil também poderão ser testados.

\section{Referências}

AGOSTINO, Maria Rosario; DRAGO, Danilo; SILIPO, Damiano B. The value relevance of IFRS in the European banking industry. Review of Quantitative Finance and Accounting, v. 36, n. 3, p. 437-457, 2010.

ALFORD, Andrew; JONES, Jennifer; LEFTWICH, Richard; ZMIJEWSKI, Mark. The relative informativeness of accounting disclosures in different countries. Journal of Accounting Research. v. 31 (supl.), p. 183-223, 1993.

ALI, A.; HWANG, L. S. The level of alignment of financial and tax accounting and the value relevance of financial accounting data: evidence from cross-country comparison. Working Paper, University of Arizona, Tucson, AZ, 1997.

ALSALMAN, Ahmad M. The value relevance of accounting numbers and the implications for international accounting standards harmonization: evidence from Saudi Arabia and Kuwait. 2003. 115 f. Dissertation (Doctor of Philosophy) - Florida Atlantic University. Boca Raton, Florida, 2003.

ALVES, Maria do Céu Gaspar; ANTUNES, Eduardo Cameira. A implementação das normas internacionais de contabilidade na Europa - um estudo comparativo. Universidade da Beira Interior, Departamento de Gestão e Economia, mai. 2010.

AMIR, Eli; HARRIS, Trevor S.; VENUTI, Elizabeth K.A Comparison of the value-relevance of U.S. versus Non-U.S. GAAP accounting measures using Form 20-F reconciliations. Journal of Accounting Research, v. 31, (supl.), p. 230-264, 1993.

ARROW, Kenneth J. Informational Structure of the Firm. The American economic Review, volume 75, Issue 2, papers and proceedings of the ninety-seventh annual meeting of the American economic association (May, 1985) 303-307.

BALL, Ray; KOTHARI, S. P.; ROBIN, Ashok. The effect of international institutional factors on properties of accounting earnings. Journal of Accounting and Economics. v. 29, n. 1, p. 1-51, fev. 2000. 
BALL, Ray; ROBIN, Ashok; WU, Joanna S. Incentives versus standards: properties of accounting income in four East Asian countries. Journal of Accounting and Economics. v. 36, n. 1-3, p. 235-270, dec. 2003.

BARTH, Mary E.; BEAVER, Willian H.; LANDSMAN, Wayne R. The relevance of the value relevance literature for financial accounting standard setting: another view. Journal of Accounting and Economics, v. 31, p. 77-104, sep. 2001.

BARTH, Mary E.; LANDSMAN, Wayne R.; LANG, Mark H. International accounting standards and accounting quality. Journal of Accounting Research. v. 46, n. 3, p. 467-498, jun. 2008.

BEISLAND, Leif Atle. A Review of the value relevance literature. The Open Business Journal, v. 2, p. 7-27, 2009.

BERLE, Adolf A.; MEANS, Gardiner C. A moderna sociedade anônima e a propriedade privada. Trad. Dinah de Abreu Azevedo. 3. ed. São Paulo: Nova Cultural, 1988.

BRASIL. Lei $\mathbf{n}^{\mathbf{0}}$. 11.638/07. Altera e revoga dispositivos das Leis $\mathrm{n}^{\mathrm{o}}$. 6.404/76 e $\mathrm{n}^{\mathrm{o}}$. 6.385/76, estende às sociedades de grande porte, disposições relativas à elaboração e divulgação de demonstrações financeiras. Disponível em: <http://www.planalto.gov.br/ccivil_03/_ato20072010/2007/lei/111638.htm> Acesso em: 01 ago. 2011.

CARVALHOSA, Modesto. Comentários à Lei de Sociedades Anônimas: lei nº 6404 de 15 de dezembro de 1976, com as modificações das leis $\mathrm{n}^{\circ} 9457$ de 5 de maio de 1997 e $\mathrm{n}^{\circ} 10.303$ de 31 de outubro de 2001. São Paulo: Saraiva, 2003.

CFC, Conselho Federal de Contabilidade. Resolução CFC no 1.055/05. Cria o Comitê de Pronunciamentos Contábeis - (CPC), e dá outras providências. 2005. Disponível em: $<$ http://www.cfc.org.br/sisweb/sre/detalhes_sre.aspx?Codigo=2005/001055>. Acesso em: 01 out. 2011.

CLARKSON, Peter et al. The Impact of IFRS adoption on the value relevance of book value and earnings. Journal of Contemporary Accounting \& Economics, v. 7, n. 1, p. 1-17, jun. 2011.

CORMIER, Denis et al.. Incentives, and value-relevance: some French evidence. Journal of International Accounting Research. v. 8, n. 2, p. 1-22, 2009.

COMISSÃO DE VALORES MOBILIÁRIOS (CVM). Deliberação CVM, n⿳ 647, de 2 de Dezembro de 2010. Disponível em:

$<$ http://www.cvm.gov.br/asp/cvmwww/atos/Atos_Redir.asp?Tipo=D\&File=/deli $\backslash$ deli647.doc >. Acesso em: 01 out. 2011. 
CUNHA, Jacqueline A. V.; COELHO, Antonio C. Regressão linear múltipla. In: CORRAR, Luiz J.; PAULO, Edilson; DIAS FILHO, José M. Análise multivariada: para os cursos de administração, ciências contábeis e economia. São Paulo: Atlas, 2009.

DALMÁCIO, Flávia Zóboli. Mecanismos de governança e acurácia das provisões dos analistas do mercado brasileiro: uma análise sob a perspectiva da teoria da sinalização. 2009. 232 f. Tese (Doutorado em Ciências Contábeis) - Programa de Pós-Graduação em Ciências Contábeis da Faculdade de Economia, Administração e Contabilidade Departamento de Contabilidade e Atuária da Universidade de São Paulo, São Paulo, 2009.

DIAS FILHO, José Maria. A linguagem utilizada na evidenciação contábil: uma análise de sua compreensibilidade à luz da teoria da comunicação. Caderno de Estudos, São Paulo, FIPECAFI, v.13, nº 24, p.38-49, jul./dez. 2000.

D'ARCI, Anne. Accounting classification and the international harmonization debate: an empirical investigation. Accounting Organizations and Society, v. 26, issues 4-5, p. 327 349, may/jul. 2001.

EISENHARDT, Kathleen M. Agency theory: an assessment and review. Academy of Management Review. v. 14, n. 1, p. 57-74, 1989.

FAMÁ, Rubens et al. Existe relação entre disclosure e governança corporativa no Brasil? In: ENANPAD. 30., 2005, Salvador. Anais... Salvador, 2005.

FARIA; Ana Cristina; QUEIROZ, Mario Roberto Braga de. Demanda de profissionais habilitados em contabilidade internacional no mercado de trabalho da cidade de São Paulo. Revista Universo Contábil, Blumenau, v. 5, n. 1, p. 55-71, jan./mar. 2009.

FÁVERO, Luiz P. et al. Análise de dados: modelagem multivariada para tomada de decisões. Rio de Janeiro: Elsevier, 2009.

FILIP, Andrei. IFRS and the value relevance of earnings: evidence from the emerging market of Romania. International Journal of Accounting, Auditing and Performance Evaluation, v. 6, n. 2-3, 2010.

GJERDE, Oystein; KNIVSFLA, Kjell; SAETTEM, Frode. The value-relevance of adopting IFRS: evidence from 145 NGAAP restatements. Journal of International Accounting, Auditing and Taxation, v. 17, n. 2, p. 92-112, 2008.

HUNG, Mingyi. Accounting standards and value relevance of financial statements: an international analysis. Journal of Accounting and Economics. v. 30, p. 401-420, 2001.

IATRIDIS, George. International financial reporting standards and the quality of financial statement information. International Review of Financial Analysis, In press, 2010.

IATRIDIS, George; ROUVOLIS, Sotiris. The post-adoption effects of the implementation of 
international financial reporting standards in Greece. Journal of International Accounting, Auditing and Taxation. v. 19, p. 55-65, 2010.

INSTITUTO BRASILEIRO DE GOVERNANÇA CORPORATIVA . Código das melhores práticas de governança corporativa. São Paulo, SP: IBGC, 2010. p. 74.

INSTITUTO DOS AUDITORES INDEPENDENTES DO BRASIL (IBRACON). NPC norma e procedimento de contabilidade, 2002.

JENSEN, Michael C.; MECKLING. Willian H. Theory of the firm: managerial behavior, agency costs and ownership structure. Journal of Financial Economics, v. 3, n. 4, p. 305360, oct. 1976.

KARAMPINIS, Nikolaos; HEVAS, Dimosthenis. The effect of the mandatory application of IFRS on the value relevance of accounting data: some evidence from Greece. European Research Studies. v. XII, n. 1, p. 73-100, 2009.

KOUSENIDIS, Dimitrios V.; LADAS, Anestis C.; NEGAKIS, Christos I. Value relevance of accounting information in the pre-and post-IFRS accounting periods. European Research Studies, v. XIII, n. 1, p. 143-152, 2010.

KROENKE, Adriana; CUNHA, Jacqueline Veneroso Alves da. Harmonização contábil: um estudo bibliométrico no Congresso USP e EnANPAD de 2004 a 2007. In: SEMEAD Empreendedorismo em Organizações. 11, 2008, São Paulo. Anais... São Paulo: USP, 2008.

LANG, Mark; RAEDY, Jana S.; WILSON, Wendy. Earnings management and cross listing: are reconciled earnings comparable to us earnings? Journal of Accounting and Economics, Amsterdam, v. 42, n. 1/2, p. 255-338, oct. 2006.

LANG, Mark; RAEDY, Jana S.; YETMAN, M. How representative are firms that are cross listed in the United States? An analysis of accounting quality. Journal of Accounting Research, v. 41, p. 363-386, 2003.

LEMES, Sirlei; CARVALHO, Luiz Nelson Guedes de. efeito da convergência das normas contábeis brasileiras para as normas internacionais do IASB. In: Congresso USP de Controladoria e Contabilidade, 4., 2004, São Paulo. Anais... São Paulo: USP, 2004.

LUSTOSA, Eliane. Escândalos corporativos e boas práticas de governança. Revista RI, Rio de Janeiro, n. 77, p. 17-18, jul. 2004.

MILLER, Merton H.; MODIGLIANI, Franco. Some estimates of the cost of capital to the electric utility industry 1954-57. The American Economic Review, v. 56, n. 3, p. 333-391, jun. 1966.

NIYAMA, Jorge Katsumi.Contabilidade internacional. São Paulo: Atlas, 2005. 
OLIVEIRA, José Júnior de. O novo mercado da B\&MF Bovespa e o desenvolvimento do mercado de capitais brasileiro. 2009. 199 f. Dissertação (Mestrado) - Universidade Federal do Rio Grande do Sul - UFRGS. Porto Alegre, 2009.

RANGEL, Leandro de Almeida; ANDRADE, George Albin Rodrigues de. A aplicação da governança corporativa como instrumento de redução do gerenciamento de resultados nas empresas de capital aberto. In: SEGET, Simpósio de Excelência em Gestão e Tecnologia, 2., 2005, Rio de Janeiro. Anais... Rio de Janeiro, 2005.

SANTOS, Edilene Santana; CALIXTO, Laura. Impactos do início da harmonização contábil internacional (Lei 11.638/2007) nos resultados das empresas abertas. RAE -Eletrônica, v. 9, n. 1 , art. 5, jan./jun. 2010 .

SEGATTO-MENDES, Andréa Paula. Teoria de agência aplicada à análise de relações entre os participantes dos processos de cooperação tecnológica universidade - empresa. 2001. 146 f. Tese (Doutorado em Administração) - Departamento de Administração da Faculdade de Economia, Administração e Contabilidade da Universidade de São Paulo USP. São Paulo, 2001.

SILVEIRA, Alexandre Di Maceli da. Governança corporativa e estrutura de propriedade: determinantes e relação com o desempenho das empresas no Brasil. 2004. 250 f. Tese (Doutorado em Administração) - Programa de Pós-Graduação em Administração da Faculdade de Economia, Administração e Contabilidade - USP. São Paulo, 2004.

WATTS, Ross; ZIMMERMAN, Jerold L. Positive accounting theory: a ten year perspective. The Accounting Review, v. 65, n. 1, p. 131-156, 1990.

WHITE, John J. A comparison of the relative value relevance of accounting earnings and book values in Germany, Japan and The U. S. 1999. 203 f. Dissertation (Doctor of Philosophy).University of Arkansas, 1999. 
